\title{
Effect of Gluconacetobacter xylinus cultivation conditions on the selected properties of bacterial cellulose
}

\author{
Karol Fijałkowski ${ }^{1}$, Anna Żywicka ${ }^{1}$, Radosław Drozd ${ }^{1}$, Marian Kordas², Rafał Rakoczy ${ }^{2 *}$ \\ ${ }^{1}$ West Pomeranian University of Technology, Szczecin, Department of Immunology, Microbiology and Physiological \\ Chemistry, al. Piastów 45, 70-311 Szczecin, Poland \\ ${ }^{2}$ West Pomeranian University of Technology, Szczecin, Institute of Chemical Engineering and Environmental Protection \\ Processes, Faculty of Chemical Technology and Engineering, al. Piastów 42, 70-311 Szczecin, Poland \\ "Corresponding author: e-mail: rafal.rakoczy@zut.edu.pl
}

\begin{abstract}
The aim of the study was to analyze the changes in the parameters of bacterial cultures and bacterial cellulose (BC) synthesized by four reference strains of Gluconacetobacter xylinus during 31-day cultivation in stationary conditions. The study showed that the most visible changes in the analyzed parameters of $\mathrm{BC}$, regardless of the bacterial strain used for their synthesis, were observed in the first 10-14 days of the experiment. It was also revealed, that among parameters showing dependence associated with the particular bacterial strain were the rate and period of $\mathrm{BC}$ synthesis, the growth rate of bacteria anchored to the cellulose fibrils, the capacity to absorb water and the water release rate. The results presented in this work may be useful in the selection of optimum culturing conditions and period from the point of view of good efficiency of the cellulose synthesis process.
\end{abstract}

Keywords: bacterial cellulose, bacterial culture, cultivation time, culture conditions, Gluconacetobacter xylinus.

\section{INTRODUCTION}

Gluconacetobacter xylinus is one of the most commonly studied microorganisms with the ability to synthesize bacterial cellulose (BC) ${ }^{1}$. It is a Gram-negative bacterium, strictly aerobic, capable of producing cellulose extracellularly at temperatures between 25 and $30^{\circ} \mathrm{C}$ and $\mathrm{pH}$ from 3 to 7, using different sources of carbon and nitrogen $^{2}$. This bacterium was also reported as the most efficient BC producer ${ }^{3}$. In terms of chemical structure, bacterial cellulose is identical to that produced by plants. However, it exhibits a higher crystallinity ${ }^{4}$, water-holding capacity ${ }^{5}$, degree of polymerization ${ }^{6}$, mechanical strength and purity ${ }^{2}$. When the bacteria are cultivated in static culture conditions, the $\mathrm{BC}$ is synthetized as a cellulose pellicle situated on the broth surface. In this case it is assumed that the bacteria immobilize themselves in the cellulose to maintain their location between a substraterich surface and the oxygen-rich air ${ }^{7}$.

$\mathrm{BC}$ is applied in such areas as biomedicine, paper production, textile industry and environmental protection ${ }^{\mathbf{8}, 9}$. However, the relatively high cost of $\mathrm{BC}$ production limits its application in the production of high value-added products and specialty chemicals $7, \mathbf{1 0}, \mathbf{1 1}$. The yield of a $\mathrm{BC}$ biosynthesis process depends on such factors as temperature, ratio of the surface area to the volume of the substrate and on the time of synthesis ${ }^{12,13}$. It is considered that a reduction of the cost of $\mathrm{BC}$ synthesis can be achieved mainly by improving fermentation efficiency ${ }^{14}$. For this purpose, various studies involving modification and optimization of the culture conditions e.g. medium composition, temperature of incubation or incubation time and the development of novel technologies have been conducted intensively all over the word ${ }^{3,7,12,15}$. Based on the literature review, it was found that so far there have been few data describing the most important changes occurring during the cultivation of G. xylinus and the biosynthesis of cellulose. Some of the information is offered in the study by Sheykhnazaria et al. ${ }^{16}$ (FT-IR spectra, X-ray diffraction patterns, microorganism morphology and its distribution in the cellulose after 7 , 14 and 21 days of the culture) and by Hornung et al. ${ }^{7}$ (dry mass of the $\mathrm{BC}$ layer, concentration of glucose in the substrate solution or number of cells immobilized in the cellulose, measured 30-50 days of the culture, depending on the experiment). However, to the best of our knowledge, no analysis showing the dependency between BC parameters and the G. xylinus strain has so far been published.

In order to optimize the production of $\mathrm{BC}$, it is necessary to characterize microbial growth, product formation and substrate utilization by the microorganisms. In addition, it is imperative to identify how these processes are affected by the time of bacterial cultivation ${ }^{7}$. The determination of a such dependence would be beneficial in establishing the basic conditions for G. xylinus culture in order to select the most appropriate culturing period in terms of good efficiency of the $\mathrm{BC}$ synthesis process and to obtain cellulose with the desired properties. Therefore, the aim of the study was to analyze the changes in the basic parameters of cultures and the cellulose synthesized by various strains of G. xylinus during 31-day cultivation in stationary conditions. The investigation whether the changes in physicochemical properties differ between individual strains, and if so, whether this variation is associated with specific parameters relating to $\mathrm{BC}$ biosynthesis, was also included.

\section{MATERIAL AND METHODS}

\section{Microorganisms and culture conditions}

Prior to the experiment, 7-day cultures of G. xylinus ATCC 53524 (American Type Culture Collection), DSM 5602 (Deutsche Sammlung von Mikroorganismen und Zellkulturen - German Collection of Microorganisms and Cell Cultures), G. xylinus DSM 46602 and G. xylinus DSM 46604 were shaken and $100 \mu \mathrm{L}$ of the obtained bacterial suspensions were used to inoculate $25 \mathrm{~mL}$ of Herstin-Schramm (HS) medium in $50 \mathrm{~mL}$ plastic tubes 
with caps featuring 8 holes and a specific capillary pore filter membrane with a pore size of $0.2 \mu \mathrm{m}$ providing gas exchange (CELLSTAR ${ }^{\circledR}$ CELLreactor, Polypropylene Filter Top Tube, Greiner Bio-One, USA). The BC synthesis was conducted at $28^{\circ} \mathrm{C}$ for 31 days. The $\mathrm{BC}$ pellicles were harvested from the medium after 3 days of cultivation and then after each 2 days, rinsed with water, wiped carefully with filter paper and weighed on an analytical balance (WTB 2000 Radwag, Poland).

In order to minimize the variation of the results, for each time point, 8 different cultures were performed (4 samples were used to assess cellular parameters, and 4 to analyse cellulose-related properties). The appropriate order of individual analysis types described below e.g. weighing, water related parameters, IR spectra and degree of polymerization, allowed to use all 4 samples of the cellulose for each test.

\section{Determination of $\mathrm{BC}$ production}

The $\mathrm{BC}$ was harvested from the medium and weighed on an analytical balance (accuracy $0.0001 \mathrm{~g}$, WTB 2000 Radwag, Poland). Subsequently, the $\mathrm{BC}$ was purified in $0.1 \mathrm{M} \mathrm{NaOH} / 80^{\circ} \mathrm{C} / 30 \mathrm{~min}$. to remove bacterial cells and medium components and then rinsed with water. The $\mathrm{NaOH}$ treatment procedure was repeated three times. In the next step, the cellulose pellicle was dried in an oven (EV-50, Trade Raypa, Spain) at $60^{\circ} \mathrm{C}$ overnight, weighed again on an analytical balance and subjected to a series of analysis as described below.

\section{Determination of water related properties}

To perform the water swelling assessment, the cellulose pellicles were cut into $1 \mathrm{~cm}^{2}$ samples, dried at $60^{\circ} \mathrm{C}$ for $6 \mathrm{~h}$ to remove any water content and weighed using an analytical balance. In the next step, the samples were immersed in distilled water till there was no further water absorption (approx. $1 \mathrm{~h}$ ), wiped carefully with filter paper and weighed. The results are shown as percentage equilibrium degree of swelling (\%SRE) $)^{17}$ calculated using the following formula:

$\% \mathrm{SRE}=\frac{\left(\mathrm{W}_{\infty}-\mathrm{W}_{\mathrm{dry}}\right)}{\mathrm{W}_{\mathrm{dry}}} 100 \%$

where:

$\mathrm{W}_{\infty}$ is the weight of $\mathrm{BC}$ at swelling equilibrium $\mathrm{BC}$ and $\mathrm{W}_{\mathrm{dry}}$ is the weight of the dry sample.

To determine the percentage of water release value (\%WRV), the initial wet weights of the $\mathrm{BC}$ samples were measured on the analytical balance as stated above. Then the samples were continuously weighed during incubation at $25^{\circ} \mathrm{C}$ at different time intervals until a constant weight of the dry sample was achieved. The WRV value ${ }^{18}$ was calculated from the equation (2):

$\% \mathrm{WRV}=\frac{\left(\mathrm{W}_{\text {dwet }}-\mathrm{W}_{\text {dry }}\right)}{\mathrm{W}_{\text {dwet }}} 100 \%$

where:

$\mathrm{W}_{\mathrm{dwet}}$ is the weight of the swollen $\mathrm{BC}$ during drying and $\mathrm{W}_{\mathrm{dry}}$ is the weight of the dry sample.

\section{Degree of polymerization measurement}

The degree of polymerization was determined by the measurement of viscosity of $\mathrm{BC}$ dissolved in $0.5 \mathrm{M}$ solution of copper (II)-ethylenediamine (CUEN) using a capillary Ubbelohde viscometer (No. 1, Labit, Poland) as described by Tsouko et al. ${ }^{\mathbf{1 9}}$.

\section{Culture medium characterization}

At each time point, the $\mathrm{pH}$ was determined in the residual culture medium using a $\mathrm{pH}$ meter (Elmetron, Poland). The concentration of glucose in the culture medium was determined enzymatically using the Glucose Assay Kit (BioMaxima, Poland) according to the manufacturer's protocol. The results were expressed as a percentage of glucose remaining in the $\mathrm{H}-\mathrm{S}$ medium during cultivation.

\section{Quantification of G. xylinus cells}

The growth rate of BC-producing bacteria was determined twice. For the first time in liquid H-S medium, after cellulose pellicle removal from the culture tube (cells in medium) and for the second time after digestion of the cellulose pellicle with cellulose (cells in cellulose). For the digestion, the cellulose pellicles were washed in distilled water, transferred to $5 \mathrm{~mL}$ of the solution of cellulase (Sigma-Aldrich, Germany) in 0.05 $\mathrm{M}$ citrate buffer ( $\mathrm{pH} 4.8)$ and incubated with shaking for $24 \mathrm{~h}$ at $35^{\circ} \mathrm{C}$. Then, the samples consisting of the culture medium or suspension obtained after digestion with cellulase were centrifuged for $20 \mathrm{~min}$ at 1500 . The obtained pellets were washed in PBS (Phosphate Buffered Saline, Sigma-Aldrich, Germany), centrifuged at 1500 for $20 \mathrm{~min}$ and restored to the original volume with PBS.

The number of microorganisms was determined using AlamarBlue cell proliferation assay (ThermoFisher, USA). Two hundred $\mu \mathrm{L}$ of the obtained bacteria suspension was transferred into wells on a black 96-well microtitre plate (Becton Dickinson and Company, USA). Twenty $\mu \mathrm{L}$ of AlamarBlue were then added to each well. The plates were sealed and incubated for $1 \mathrm{~h}$ at $28^{\circ} \mathrm{C}$. The fluorescence signal was measured using microplate fluorescence reader (Plate Reader AF2200, Eppendorf, USA) at wavelengths of $540 \mathrm{~nm}$ excitation and $590 \mathrm{~nm}$ emission.

\section{Infrared spectroscopy of bacterial cellulose}

The IR spectra of bacterial cellulose were analyzed by the Attenuated Total Reflectance Fourier Transform Infrared Spectroscopy (ATR-FTIR) method, using ALPHA FT-IR Spectrometer (Burker Co., Germany). The spectra were collected in the range of $4000-400 \mathrm{~cm}^{-1}$. For each BC sample, 64 scans of the resolution of $8 \mathrm{~cm}^{-1}$ were performed. The spectra were processed using the Omnic Software and normalized to 1 at $1160 \mathrm{~cm}^{-1}$ (COC stretching mode for glucose rings).

\section{RESULTS AND DISCUSSION}

As reported by Hesse and Kondo ${ }^{20}$ the cellulose secreted is randomly deposited behind the microorganism to produce a membrane of a three-dimensional network. It has also been reported that the product formation within a static culture starts with the formation of island- 
-like cellulose fragments on the broth surface. Next, the fragments close together to form a thin cellulose pellicle. The thickness of this layer increases with synthesis time to approx. $2-4 \mathrm{~cm}$ within 10 to 28 days. After this time no further significant increase in cellulose synthesis is observed $^{7}$. Similar observations were also made in the current study. The first, thin cellulose layer was observed from the 3rd day of the cultivation, regardless of the G. xylinus strain, and this time point was determined as the beginning of our experiment. The mass of the cellulose increased constantly up to 15-17 days of cultivation (Fig. 1). After that time, for 3 strains, no further increase in BC weight was observed (Fig. 1 A, C, D). In contrast, the G. xylinus strain DSM 46602 synthetized cellulose for the entire time of the experiment, although after 15 days the synthesis became visibly slower (Fig. 1 B). As can be seen from Figure 1, the number of bacterial cells in the cellulose matrix increased along with the cellulose synthesis. It can also be noticed that bacterial growth continued for 6 days after the cellulose production stopped; however, reproduction rate visibly slowed down. After 21-23 days (depending on the bacterial strain) the growth slightly decreased and then remained at the same level until the end of the cultivation time. As reported by Hornung et al. ${ }^{7}$, the floating cellulose pellicle becomes a barrier for the glucose mass transfer in the later stages of its synthesis. In contrast to the bacteria anchored to the cellulose fibrils, the growth rate of $G$. xylinus in a suspension increased rapidly to 7 days of the culture, and then decreased until 19-23 days (Fig. 1). After that time, the growth rate leveled up and remained at a similar level until the end of the experiment. It is well known that $G$. xylinus is an obligate aerobic microorganism ${ }^{1}$. The cellulose keeps the bacteria in close contact with the oxygen from the air. Therefore, the observation from the current study showing a declining trend of viable bacterial cells in the medium after 6 days of cultivation should be explained by the deficiency of oxygen resulting from the creation of the cellulose pellicle on the surface of the medium. As previously reported, formation of the cellulose pellicle prevents gas exchange between the medium and the atmosphere ${ }^{7}$.

Glucose is the primary substrate for the synthesis of cellulose. It is incorporated in a 4-step metabolic pathway placed in cytosol and converted to UDP-glucose. In the next step, cellulose synthase located in the bacterial cell wall catalyzes the polymerization of UDP-glucose to poly $\beta-1-4$ glucan $^{21}$. The process of polymerization of UDP-glucose to poly $\beta-1-4$ glucan can be disrupted by such environmental conditions as oxygenation, $\mathrm{pH}$ or temperature ${ }^{22}$. Glucose can also be readily converted to gluconic acid which significantly affects the $\mathrm{pH}$ of the medium. This may also affect the efficiency of the BC a)

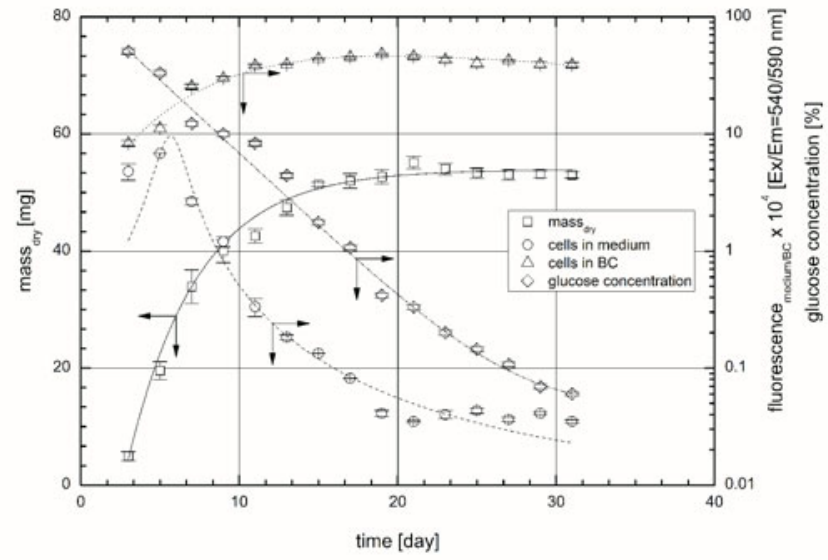

b)

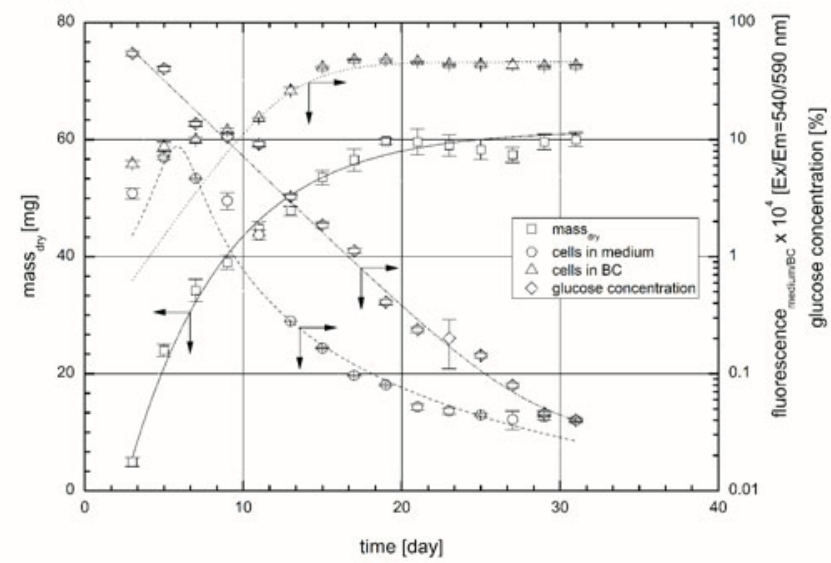

c)

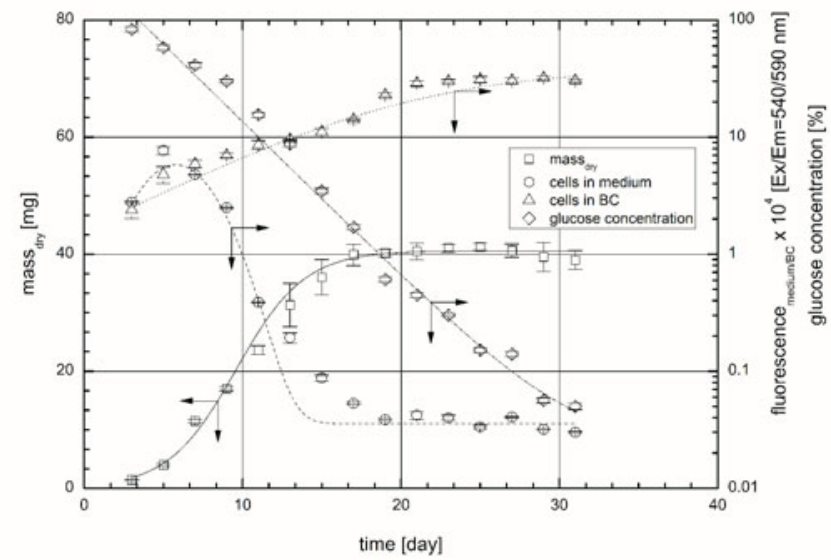

d)

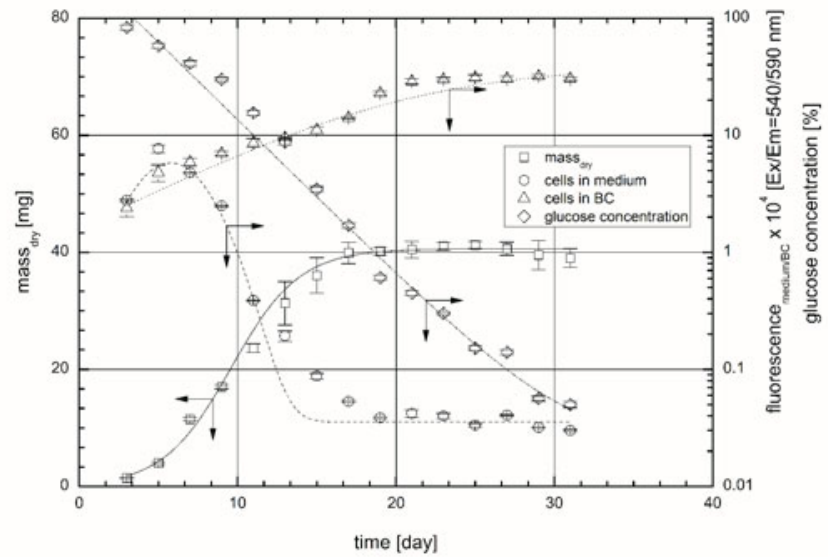

Figure 1. The rate of bacterial growth and cellulose synthesis and the changes in glucose concentration depending on the culture period and G. xylinus bacterial strain: A) ATCC 53524, B) DSM46602, C) DSM46604, D) DSM5067

mass $_{\text {dry }}$ - weight of cellulose after purification $0.1 \mathrm{M} \mathrm{NaOH} / 80^{\circ} \mathrm{C} / 30 \mathrm{~min}$. and drying at $60^{\circ} \mathrm{C}$ overnight; cells in medium - number of bacterial cells in $\mathrm{H}-\mathrm{S}$ medium based on the fluorescence signal of AlamaBlue reagent; cells in BC - number of bacterial cells in cellulose based on the fluorescence signal of AlamaBlue reagent; glucose concentration - percentage of glucose remained in $\mathrm{H}-\mathrm{S}$ medium during cultivation. 
synthesis process. The current study showed that glucose was almost entirely metabolized in the first $11-15$ days of the cultivation (Fig. 1), i.e. in the period of cellulose biosynthesis. Such findings are consistent with the observation by Keshk and Sameshima ${ }^{23}$ who reported that glucose was consumed rapidly in the early stage of incubation and almost completely (97\%) after 7 days of incubation. Interestingly, in our study even $50 \%$ of glucose was metabolized within the time when the initial layer of $\mathrm{BC}$ could be observed (3 days). Earlier reports showed that insufficient substrate supply (of e.g. glucose) to the bacteria may be one of the most important external factors limiting the yield of the surface culture ${ }^{7}$. On the other hand, as reported by Toda et al. ${ }^{24}$, in cultures where glucose is the primary carbon source, high concentration of gluconic acid can be another crucial factor responsible for the decreased synthesis of BC. The increased concentration of gluconic acid results in a decreased $\mathrm{pH}$ of the medium, which in turn reduces intracellular $\mathrm{pH}$. As a consequence, high concentration of gluconic acid can change the activity of metabolic pathways responsible for the synthesis of $\mathrm{BC}^{25}$. As is widely accepted, optimum $\mathrm{pH}$ values range from 4.5 to 7.5 with the greatest efficiency being located around 6.5 , whereas below the 3.5 value cellulose synthesis is inhibited $^{26,27}$. Although in our study glucose was metabolized relatively rapidly and the cellulose layer was formed as expected, in no case did the $\mathrm{pH}$ drop below the level which could inhibit cellulose synthesis (Fig. 2). However, based on the literature, changes in the $\mathrm{pH}$ value during the cellulose synthesis process may have a very complex character and thus it is difficult to clearly define the cause of the changes in this parameter. As an example, Yunoki et al. ${ }^{28}$ did not observe any changes in the $\mathrm{pH}$ for seven days of cultivation of G. xylinus ATCC 10245. Park et al. ${ }^{29}$ who cultivated the strain of $G$. hansenii

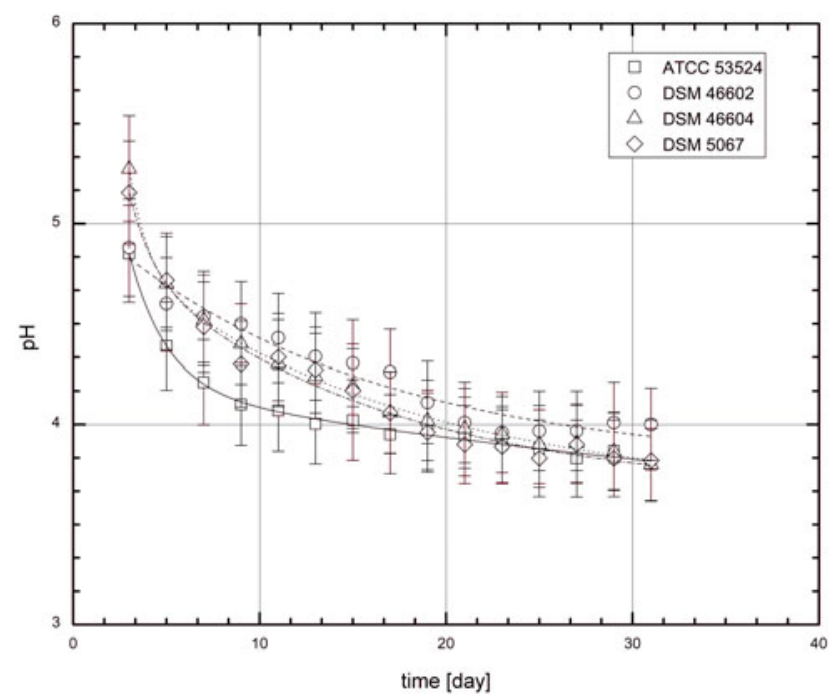

Figure 2. The $\mathrm{pH}$ of $\mathrm{H}-\mathrm{S}$ medium depending on the culture period and $G$. xylinus bacterial strain

found a decrease in $\mathrm{pH}$ to 3 units on the 5 th day of the culture. In contrast, in the study by Santos et al. ${ }^{15}$ the $\mathrm{pH}$ dropped below 3.5 after the 4th day of incubation when glucose was used as a carbon source.

The cellulose synthetized by G. xylinus contains more than $90 \%$ of water ${ }^{30}$. It also displays a great capacity to absorb water. The wet mass of BC can be 100-200 times higher than its dry weight ${ }^{31,32}$. The water resides inside the $\mathrm{BC}$ pores and is bound to the cellulose fibrils through hydrogen bonding ${ }^{33}$. The quantity of water trapped within the cellulosic scaffold depends on the strength of the physical adsorption on the fiber surface and on the density of reticulated fibers' linkage. The more space is available between the $\mathrm{BC}$ fibrils, the more water can penetrate and adsorb onto the material. Therefore, the difference in water capacity may be caused by the variances in fibril arrangement and porosity of various BC samples. The density of $\mathrm{BC}$ increases due to the secretion of more fibrils with the passage of time ${ }^{34}$. This in turn explains why the water-related properties of $\mathrm{BC}$ change along its synthesis time. The current study has shown that the $\mathrm{BC}$ obtained after 3 days displayed the highest water content as well as the highest water absorption capacity in comparison to the samples cultivated for a longer time (Fig. 3). Furthermore, cellulose pellicles obtained from cultures during consecutive days of cultivation, until the 15 th- 17 th day, were characterized by a progressively decreasing water content as well as the ability to absorb water. The drop in the water swelling capacity of cellulose was especially well seen until the 11th day of culturing. Over the next 10 days, the water content value and the capacity to swell in water declined at a slower rate, reaching stabilization at approx. 21st-23rd day. Our observation agreed with the previous results reported by Al-Shamary and $\mathrm{Al}$-Darwash ${ }^{35}$ who demonstrated that the density of $\mathrm{BC}$ increased during the cultivation, whereas water capacity decreased due to the secretion of the fibrils with time. In the study by Sheykhnazaria et al. ${ }^{16}$, SEM micrographs showed that the number of microfibril branches crossing to each other in the cellulose increased up to 14 days of its synthesis. However, further increase in synthesis time (up to 21 days) resulted in a decrease in the microfibril network.

It has also been demonstrated that the amount of water that escapes from the $\mathrm{BC}$ matrix to the environment depends on the arrangement of cellulose microfibrils ${ }^{36}$. The closely arranged microfibrils bind the water molecules more efficiently because of stronger hydrogen bonding interactions as compared to the loosely arranged microfibrils, which rather ineffectively protect the water from evaporation ${ }^{37,38}$. In the current study, the values of water release obtained for $\mathrm{BC}$ from 3 strains declined until 11-17 days (depending on the strain) and then remained at the same level until the end of the experiment (Fig. 3 A, B, C). In contrast, in the case of the cellulose produced by the strain of G. xylinus DSM 5067, the water release value constantly decreased (Fig. 3 D).

The analysis of the polymerization degree of cellulose revealed that this parameter constantly decreased for the entire period of the cellulose synthesis (Fig. 4). As reported by Tahara et al. ${ }^{39}$ the successive decrease in polymerization degree observed during cellulose synthesis can be related to the activity of the cellulase produced by most strains of G. xylinus cultivated in static culture conditions.

In light of the results obtained in the ATR-FTIR analysis, the spectra, regardless of the strain and time of $\mathrm{BC}$ synthesis, contained elements typical for BC (Fig. 5). From these analyses it can also be seen, that the intensity of bands in the individual spectral regions changes over the time of G. xylinus culture and BC synthesis. Most 
a)

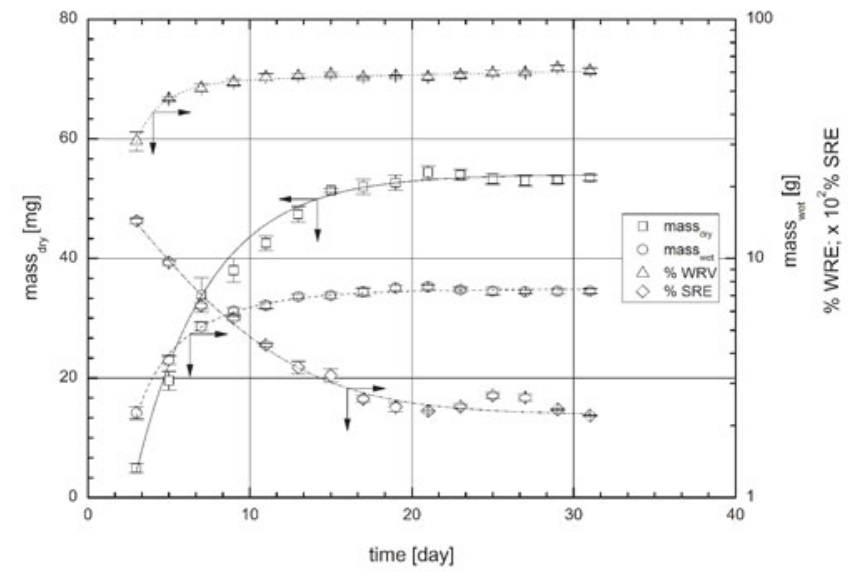

b)

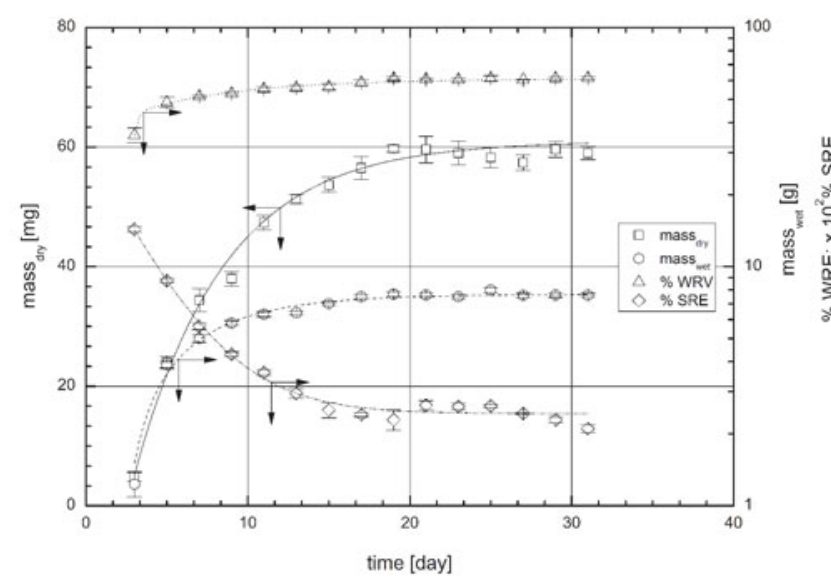

c)

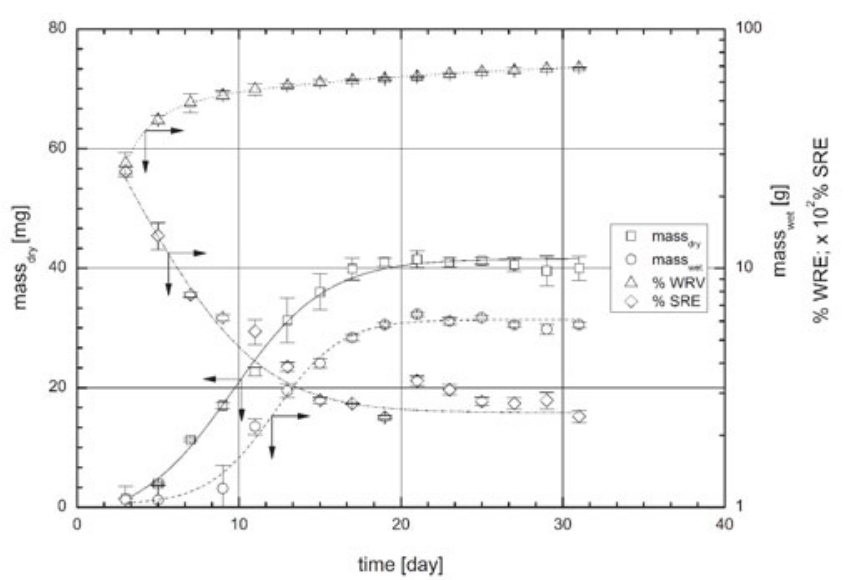

d)

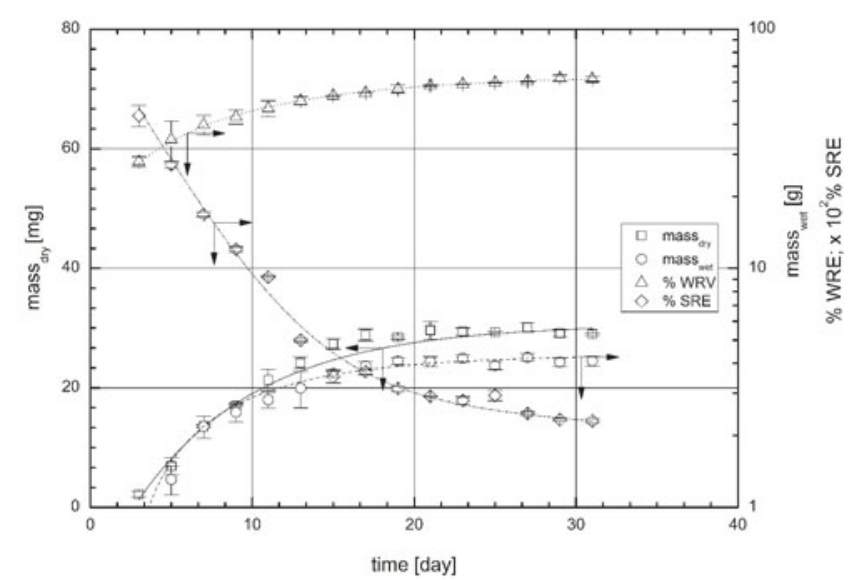

Figure 3. The dry mass and wet and water related parameters of cellulose depending on the culture period and $G$. xylinus bacterial strain: A) ATCC 53524, B) DSM46602, C) DSM46604, D) DSM5067

mass $_{\text {dry }}$ - weight of cellulose after purification $0.1 \mathrm{M} \mathrm{NaOH} / 80^{\circ} \mathrm{C} / 30 \mathrm{~min}$. and drying at $60^{\circ} \mathrm{C}$ overnight; mass wet - weight of cellulose before purification and drying; \%WRV - water release value; \%SRE equilibrium degree of swelling.

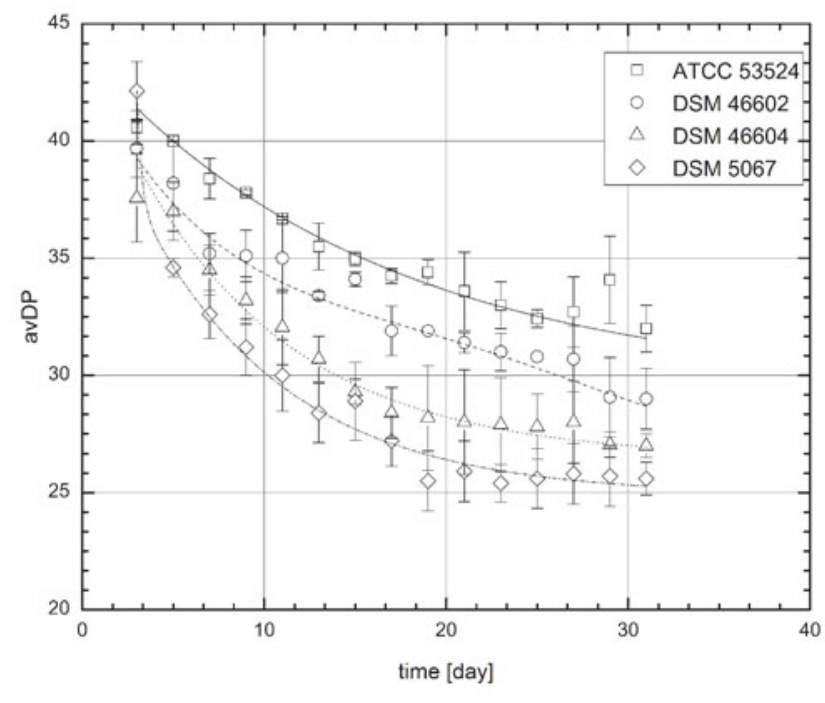

Figure 4. The polymerization degree of cellulose depending on the culture period and G. xylinus bacterial strain

likely, the changes refer to the progressive aggregation of cellulose microfibrils and the formation of an increased number of hydrogen bonds. In the range of spectrum from $1200 \mathrm{~cm}^{-1}$ to $800 \mathrm{~cm}^{-1}$ a difference in the intensity of the bands indicating the C-O group (primary and secondary alcohols) was observed. These changes indicate a progressive differentiation of the molecular structure related to the increase in the content of crystalline form and the decrease in amorphous state in cellulose. This is consistent with previous reports from Liu et al. ${ }^{40}$ who reported that plant cellulose had a different ATR-FTIR profile depending on its age. The observed differences in $\mathrm{BC}$ molecular structure can be also explained by the drop in the values of the average degree of polymerization and may indicate changes in the size of crystallites over the time of $\mathrm{BC}$ synthesis.

Summarizing, the obtained results have shown that there is a general pattern for bacterial growth and cellulose synthesis conducted by various strains of G. xylinus. The most visible changes in the analyzed parameters of $\mathrm{BC}$ were observed within the first 10-14 days of the experiment. The general trend indicated that along with the culturing time the mass of the synthetized cellulose increased which correlated with the progressive increase in the number of bacteria attached to the cellulose matrix. The beginning of the formation of the cellulose pellicle was related to a decrease in the number of cells present in the suspension form in the culture medium. Active bacteria metabolized glucose which resulted in a constant reduction of this substrate as well as the $\mathrm{pH}$ value of the culture medium. The water properties also depended on the age of the $\mathrm{BC}$ samples. The parameters demonstrating the water capacity and ability to swell in water decreased from young to old cellulose, whereas the water release 
a)

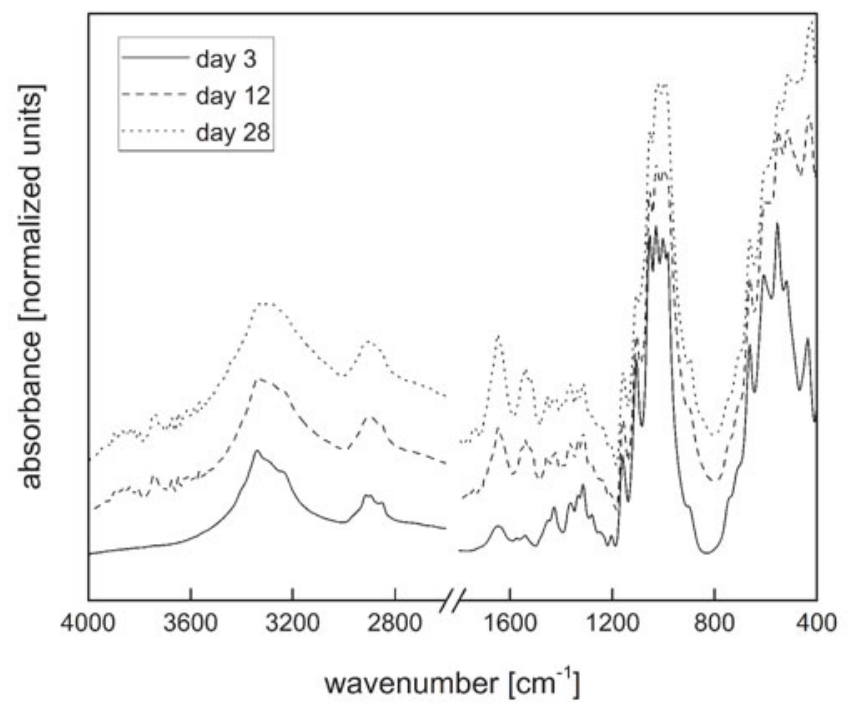

b)

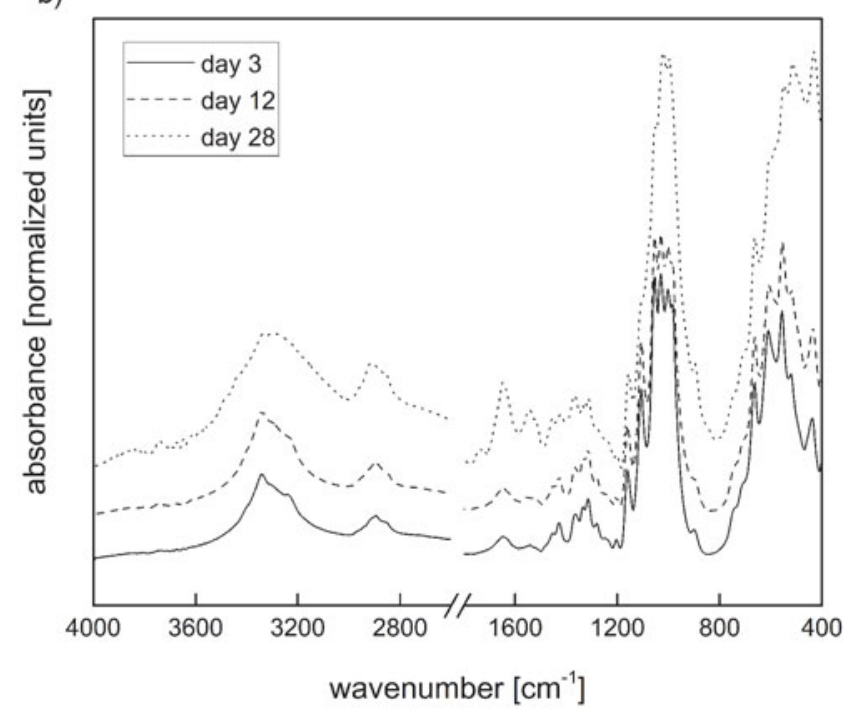

c)

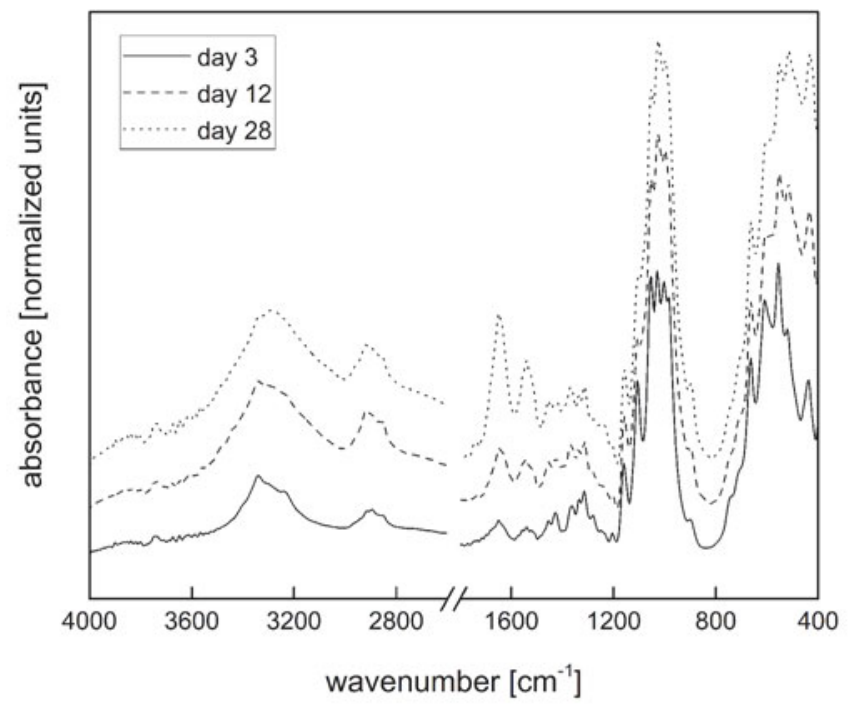

d)

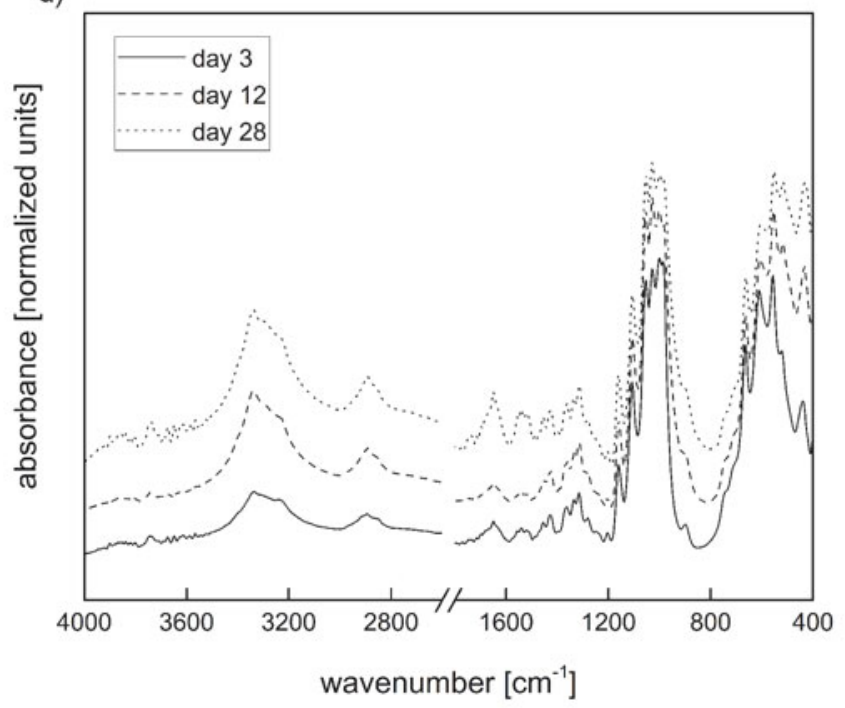

Figure 5. ATR-FTIR spectra of BC obtained after 3, 12, 28 days of synthesis for the individual bacterial strains: A) ATCC 53524, B) DSM46602, C) DSM46604, D) DSM5067

rate showed the opposite trend. Furthermore, the study showed that within the progressive cultivation time the $\mathrm{BC}$ polymerization value decreased. The results from the ATR-FTIR indicated a gradual differentiation of the molecular structure of $\mathrm{BC}$ depending on the content of crystalline and amorphous forms. It was also revealed, that among parameters showing dependence associated with the particular G. xylinus strain were the rate and period of BC synthesis, the growth rate of bacteria anchored to the cellulose fibrils, the capacity to absorb water and the water release rate.

The results obtained in the current study may be useful in the selection of optimum culturing conditions and period from the point of view of good efficiency of the cellulose synthesis process. They may also help obtain a material with the desired properties.

\section{ACKNOWLEDGMENTS}

This study was supported by the National Centre for Research and Development in Poland (Grant No. LIDER/011/221/L-5/13/NCBR/2014).

\section{LITERATURE CITED}

1. Chawla, P.R., Bajaj, I.B., Survase, S.A. \& Singhal, R.S. (2009). Microbial cellulose: fermentative production and applications. Food Technol. Biotechnol. 47(2), 107-124.

2. Castro, C., Zuluaga, R., Álvarez, C., Putaux, J.L., Caro, G., Rojas, O.J., Mondragon, I. \& Ganán, P. (2012). Bacterial cellulose produced by a new acid-resistant strain of Gluconacetobacter genus. Carbohyd. Polym. 89(4), 1033-1037. DOI: 10.1016/j.carbpol.2012.03.045.

3. Hameed, N.D., Al-Jailawi, M.H. \& Jasim, H.M. (2012). Enhancement and optimization of cellulose production by Gluconacetobacter xylinus N2. Sci. J. King Faisal Univ. (Basic and Applied Sciences) 13(2), 77-89.

4. Nakagaito, A.N., Nogi, M. \& Yano, H. (2010). Displays from transparent films of natural nanofibers. MRS Bulletin 35(3), 214-218. DOI: http://dx.doi.org/10.1557/mrs2010.654

5. Saibuatong, O.A. \& Phisalaphong, M. (2010). Novo aloe vera - bacterial cellulose composite film from biosynthesis. Carbohyd. Polym. 79(2), 455-460. DOI: 10.1016/j.carbpol.2009.08.039.

6. Dahman, Y., Jayasuriya, K.E. \& Kalis, M. (2010). Potential of biocellulose nanofibers production from agricultural renewable resources: Preliminary study. Appl. Biochem. Biotech. 162(6), 1647-1659. DOI: 10.1007/s12010-010-8946-8.

7. Hornung, M., Ludwig, M., Gerrard, A.M. \& Schmauder, H.P. (2006). Optimizing the production of bacterial cellulose in surface culture: evaluation of substrate mass transfer influences 
on the bioreaction (Part 1). Eng. Life Sci. 6(6), 546-551. DOI: 10.1002/elsc.200620162.

8. Bielecki, S., Krystynowicz, A., Turkiewicz, M. \& Kalinowska, H. (2005). Bacterial cellulose. In A. Steinbüchel \& S.K. Rhee (Eds.), Polysaccharides and Polyamides in the Food Industry (pp. 31-85). Weinheim: Wiley-VCH Verlag.

9. Huang, Y., Zhu, C., Yang, J., Nie, Y., Chen, C. \& Sun, D. (2013). Recent advances in bacterial cellulose. Cellulose 21(1), 1-30. DOI: 10.1007/s10570-013-0088-z.

10. Legge, R.L. (1990). Microbial cellulose as a specialty chemical. Biotechnol. Adv. 8(2), 303-319. DOI: 10.1016/07349750(90)91067-q.

11. Lin, S.P., Calvar, I.L., Catchmark, J.M., Liu, J.R., Demirci, A. \& Cheng K.C. (2013). Biosynthesis, production and applications of bacterial cellulose. Cellulose 20(5), 2191-2219. DOI: 10.1007/s10570-013-9994-3.

12. Ruka, D.R., Simon, G.P. \& Dean, K.M. (2012). Altering the growth conditions of Gluconacetobacter xylinus to maximize the yield of bacterial cellulose. Carbohyd. Polym. 89(2), 613-622. DOI: 10.1016/j.carbpol.2012.03.059.

13. Surma-Ślusarska, B., Presler, S. \& Danielewicz, D. (2008). Characteristics of bacterial cellulose obtained from Acetobacter xylinum culture for application in papermaking. Fibres Text. East. Eur. 4(69), 108-111.

14. El-Saied, H., Basta, A.H. \& Gobran, R.H. (2004). Research progress in friendly environmental technology for the production of cellulose products (bacterial cellulose and its application). Polym-Plast. Technol. Eng. 43(3), 797-820. DOI: 10.1081/PPT-120038065.

15. Santos, S.M., Carbajo, J.M. \& Villar, J.C. (2013). The effect of carbon and nitrogen sources on bacterial cellulose production and properties from Gluconacetobacter sucrofermentans CECT 7291 focused on its use in degraded paper restoration. BioResourses 8(3), 3630-3645.

16. Sheykhnazari, S., Tabarsa, T., Ashori, A., Shakeri, A. \& Golalipour, M. (2011). Bacterial synthesized cellulose nanofibers; Effects of growth times and culture mediums on the structural characteristics. Carbohyd. Polym. 86(3), 1187-1191. DOI: 10.1016/j.carbpol.2011.06.011.

17. Păvăloiu, R.D., Stoica-Guzun, A. \& Dobre, T. (2015). Swelling studies of composite hydrogels based on bacterial cellulose and gelatin. U.P.B. Sci. Bull. Ser. B 77(1), 53-62.

18. Cheng, Q., Wang, J., McNeel, J. \& Jacobson, P. (2010). Water retention value measurements of cellulosic materials using a centrifuge technique. BioResourses 5(3), 1945-1954.

19. Tsouko, E., Kourmentza, C., Ladakis, D., Kopsahelis, N., Mandala, I., Papanikolaou, S., Paloukis, F., Alves, V. \& Koutinas, A. (2015). Bacterial cellulose production from industrial waste and by-product streams. Int. J. Mol. Sci. 16(7), 14832-14849. DOI: $10.3390 / \mathrm{ijms} 160714832$.

20. Hesse, S. \& Kondo, T. (2005). Behavior of cellulose production of Acetobacter xylinum in ${ }^{13} \mathrm{C}$-enriched cultivation media including movements on nematic ordered cellulose templates. Carbohyd. Polym. 60(4), 457-465. DOI: 10.1016/j. carbpol.2005.02.018.

21. Koizumi, S., Tomita, Y., Kondo, T. \& Hashimoto, T. (2009). What factors determine hierarchical structure of microbial cellulose - interplay among physics, chemistry and biology. Macromol. Symp. 279(1), 110-118. DOI: 10.1002/masy.200950517. 22. Ross, P., Weinhouse, H., Aloni, Y., Michaeli, D., Weinberger-Ohana, P., Mayer, R., Braun, S., de Vroom, E., van der Marel, G.A., van Boom, J.H. \& Benziman, M. (1987). Regulation of cellulose synthesis in Acetobacter xylinum by cyclic diguanylic acid. Nature 325, 279-281. DOI: 10.1038/325279a0.

23. Keshk, S. \& Sameshima, K. (2005). Evaluation of different carbon sources for bacterial cellulose production. Afr. $J$. Biotechnol. 4(6), 478-482. DOI: 10.5897/AJB2005.000-3087.

24. Toda, K., Asakura, T., Fukaya, M., Entani, E. \& Kawamura, Y. (1997). Cellulose production by acetic acid-resistant Aceto- bacter xylinum. Ferment. Bioeng. 84(3), 228-231. DOI: 10.1016/ S0922-338X(97)82059-4.

25. Park, J.K., Hyun, S.H. \& Jung, J.Y. (2004). Conversion of G. hansenii PJK into non-cellulose-producing mutants according to the culture condition. Biotechnol. Bioproc. Eng. 9(5), 383-388. DOI: 10.1007/BF02933062.

26. Çoban, E.P. \& Biyik, H. (2011). Effect of various carbon and nitrogen sources on cellulose synthesis by Acetobacter lovaniensis HBB5. Afr. J. Biotechnol. 10(27), 5346-5354. DOI: 10.5897/AJB10.1693.

27. Son, H.J., Heo, M.S., Kim, Y.G. \& Lee, S.J. (2001). Optimization of fermentation conditions for the production of bacterial cellulose by a newly isolated Acetobacter sp. A9 in shaking cultures. Biotechnol. Appl. Biochem. 33(1), 1-5. DOI: 10.1042/BA20000065.

28. Yunoki, S., Osada, Y., Kono, H. \& Takai, M. (2004). Role of ethanol in improvement of bacterial cellulose production: analysis using ${ }^{13} \mathrm{C}$-labeled carbon sources. Food. Sci. Technol. Res. 10(3), 307-313. DOI: 10.3136/fstr.10.307.

29. Park, J.K., Jung, J.Y. \& Park, Y.H. (2003). Cellulose production by Gluconacetobacter hansenii in a medium containing ethanol. Biotechnol. Lett. 25(24), 2055-2059. DOI: 10.1023/B: BILE.0000007065.63682.18.

30. Pa', E.N., Hamid, N.I.A., Khairuddin, N., Zahan, K.A., Seng, K.F. \& Siddique, B.M. (2014). Effect of different drying methods on the morphology, crystallinity, swelling ability and tensile properties of nata de coco. Sains Malaysiana 43(5), 767-773.

31. Lin, S.B., Hsu, C.P., Chen, L.C. \& Chen, H.H. (2009). Adding enzymatically modified gelatin to enhance the rehydration abilities and mechanical properties of bacterial cellulose. Food Hydrocol. 23(8), 2195-2203. DOI: 10.1016/j.foodhyd.2009.05.011. 32. Schrecker, S.T. \& Gostomski, P.A. (2005). Determining the water holding capacity of microbial cellulose. Biotechnol. Lett. 27(19), 1435-1438. DOI: 10.1007/s10529-005-1465-y.

33. Gelin, K., Bodin, A., Gatenholm, P., Mihranyan, A., Edwards, K. \& Strømme, M. (2007). Characterization of water in bacterial cellulose using dielectric spectroscopy and electron microscopy. Polymer 48(26), 7623-7631. DOI: 10.1016/j. polymer.2007.10.039.

34. Tang, W., Jia, S., Jia, Y. \& Yang, H. (2010). The influence of fermentation conditions and post-treatment methods on porosity of bacterial cellulose membrane. World J. Microb. Biotechnol. 26(1), 125-131. DOI: 10.1007/s11274-009-0151-y.

35. Al-Shamary, E.E. \& Al-Darwash, A.K. (2013). Influence of fermentation condition and alkali treatment on the porosity and thickness of bacterial cellulose membranes. The Online J. Sci. Technol. 3(2), 194-203.

36. Shezad, O., Khan, S., Khan, T. \& Park, J.K. (2010). Physicochemical and mechanical characterization of bacterial cellulose produced with an excellent productivity in static conditions using a simple fed-batch cultivation strategy. Carbohyd. Polym. 82(1), 173-180. DOI: 10.1016/j.carbpol.2010.04.052.

37. Ougiya, H., Watanabe, K., Matsumura, T. \& Yoshinaga. F. (1998). Relationship between suspension properties and fibril structure of disintegrated bacterial cellulose. Biosci. Biotech. Bioch. 62(9), 1714-1719. DOI: 10.1271/bbb.62.1714.

38. Shah, N., Ha, J.H. \& Park, J.K. (2010). Effect of reactor surface on production of bacterial cellulose and water soluble oligosaccharides by Gluconacetobacter hansenii PJK. Biotechnol. Bioproc. Eng. 15(1), 110-118. DOI: 10.1007/s12257-009-3064-6. 39. Tahara, N., Tabuchi, M., Watanabe, K., Yano, H., Morinaga, Y. \& Yoshinaga, F. (1997). Degree of polymerization of cellulose from Acetobacter xylinum BPR2001 decreased by cellulase produced by the strain. Biosci. Biotech. Bioch. 61(11), 1862-1865. DOI: 10.1271/bbb.61.1862.

40. Liu, Y., Thibodeaux, D., Gamble, G., Bauer, P. \& van Derveer, D. (2012). Comparative investigation of Fourier Transform Infrared (FT-IR) spectroscopy and X-ray Diffraction (XRD) in the determination of cotton fiber crystallinity. Appl. Spectrosc. 66(8), 983-986. DOI: 10.1366/12-06611. 